\title{
MORFOLOGIA E DESENVOLVIMENTO DO NÚCLEO VITELINICO DO LAMBARI ASTYANAX BIMACULATUS (LINNAEUS, 1758) (OSTEICHTHYES, CHARACIDAE)
}

\author{
Silvia Dantas Cangussu-Mariani ${ }^{1}$ \\ Elizete Rizzo ${ }^{1}$ \\ Nilo Bazzoli ${ }^{1}$
}

\begin{abstract}
A morphological study of the yolk nucleus in previtellogenic oocytes from A. bimaculatus has been carried out. Six phases of development were described from its formation closed to the oocyte nucleus to its dispersion in the periferic ooplasm. Histochemical techniques indicate proteins, lipids and RNA in the yolk nucleus of $\mathbf{A}$. bimaculatus, but there are no carbohydrate in this structure. The origin and functional activity of the teleost yolk nucleus are discussed.
\end{abstract}

\section{INTRODUÇÃO}

O núcleo vitelínico é um complexo justanuclear de organelas que circunda o centrossoma de ovócitos de vertebrados e invertebrados (GURAYA, 1979 revisão). Descrito pela primeira vez por Balbiani, ele recebe também outras denominações tais como: corpo de Balbiani, núcleo vitelínico de Balbiani, nuage, substância palial ou corpos semelhantes a nucléolos. Em teleósteos, o núcleo vitelínico ocorre no citoplasma dos ovócitos pré-vitelogênicos mas vários estudos indicam sua formação a partir de material nuclear (DROLLER \& ROTH, 1966; BEAMS \& KESSEL, 1973; AZEVEDO, 1984). Estudos ultra-estruturais mostram que o corpo de Balbiani é constituído de agregados de ribonucleoproteínas associadas a uma população heterogênea de organelas citoplasmáticas tais como: mitocôndrias, retículo endoplasmático, elementos do Golgi e corpos multivesiculares (SELMAN \& WALLACE, 1989 revisão). Além destas organelas, foram também observadas, em algumas espécies de peixes, lamelas anuladas as quais tem estrutura semelhante à do envoltório nuclear, apresentando inclusive poros (CRUZ-LANDIM \& CRUZ-HOFLING, 1979; GURAYA, 1979 revisão). As funções do núcleo vitelínico ainda não estão esclarecidas mas existem evidências de seu envolvimento na vitelogênese (GURAYA, 1979 revisão).

Considerando que não existem estudos pormenorizados sobre o núcleo vitelínico em peixes teleósteos brasileiros, o presente trabalho tem como objetivo estudar esta estrutura nos ovócitos do lambari-do-rabo-amarelo, Astyanax bimaculatus (Linnaeus, 1758) com a finalidade de descrever sua morfologia ao microscópio óptico, estabelecer as fases de seu desenvolvimento e determinar sua composição química. 


\section{MATERIAL E MÉTODOS}

Foram utilizadas onze fêmeas de $A$. bimaculatus em diferentes fases de maturação gonádica. Os peixes foram capturados no período de $1987 / 88$, no rio Paranaiba, MG, no trecho a ser inundado pela futura Usina Hidroelétrica de Bocaina. Para os estudos histológicos, fragmentos de ovários foram fixados em líquido de Bouin durantes quatro horas, incluidos em parafina ou paraplast e cortados com 4 a $7 \mu \mathrm{m}$ de espessura. Os cortes foram corados pelas técnicas de hematoxilina-eosina, tricrômico de Gomory e tricrômico de Mallory. Alguns fragmentos de ovários foram fixados em formol a $10 \%$, cortados em criostato com 10 a $12 \mu \mathrm{m}$ de espessura para histoquimica de lípides. A análise do conteúdo do núcleo vitelínico foi feita através das seguintes técnicas histoquímicas, conforme descritas por PEARSE (1985): para detecção de carboidratos: ácido periódicoSchiff (PAS), alcian blue 8 GX-Sigma em pH 2,5 e em pH 0,5; para detecção de proteínas com radical $\mathrm{NH}_{2}$ : ninhidrina-Schiff, para detecção de lípides: Sudan black B e para detecção de RNA: methyl green-pyronin.

\section{RESULTADOS}

O desenvolvimento ovocitário de $A$. bimaculatus foi dividido em 4 estádios de acordo com a classificação de BAZZOLI \& RIZZO (1990): $O_{1}$ = ovócito jovem; $\mathrm{O}_{2}=$ ovócito pré-vitelogênico; $\mathrm{O}_{3}=$ ovócito com vesículas corticais e $\mathrm{O}_{4}=$ ovócito com glóbulos de vitelo. O núcleo vitelínico apresenta-se como estrutura basófila, de morfologia variável, e é característico dos ovócitos 2 , pré-vitelogênicos. Seu desenvolvimento foi dividido em 6 fases (Figs. 1 a 6) baseando-se nas modificações morfológicas observadas desde o seu aparecimento na região justanuclear até sua dispersão no ooplasma periférico, quando surgem as vesículas corticais:

Fase 1: o núcleo vitelínico apresenta-se como pequena estrutura esférica, densa, fortemente basófila, circundada por halo claro e em continuidade com o núcleo do ovócito. Nesta fase, o citoplasma do ovócito, também basófilo, apresenta-se finamente granular, seu núcleo é relativamente grande, vesiculoso, central e com nucléolos acolados à face interna do envoltório nuclear (Fig. 7).

Fase 2: o núcleo vitelínico perde a continuidade com o núcleo do ovócito e gradativamente afasta-se em direção ao citoplasma periférico. O halo claro persiste e uma área central acidófila pode ser observada no núcleo vitelínico da maioria dos ovócitos.

Fase 3: nesta fase, o halo claro é preenchido por material finamente granular. Deste modo, o núcleo vitelínico apresenta duas regiões distintas: região interna densa e região externa finamente granular (Fig. 8).

Fase 4: o ovócito apresenta-se mais desenvolvido, o núcleo vitelínico desorganiza-se originando granulações grosseiras, fortemente basófilas, que ocupam quase todo ooplasma. Fase 5: o conteúdo do núcleo vitelínico ocupa posição periférica no ooplasma, formando um colar contínuo de grânulos basófilos (Fig. 9). O ovócito apresenta-se maior que nas fases anteriores, seu núcleo é central, de contorno irregular, e com nucléolos ainda provocando protusões no envoltório nuclear.

Fase 6: o conteúdo do núcleo vitelínico, formado pelo colar de grânulos basófilos periféricos, dispersa-se gradativamente no ooplasma à medida que surgem as vesículas corticais (Fig. 10).

No núcleo vitelínico de $A$. bimaculatus detectou-se a presença de proteínas, li- 
Vol. 7(3), 1990

pides e RNA devido à reação positiva às técnicas de ninhidrina-Schiff, Sudan black $\mathrm{B} e$ methyl greenpyronin, respectivamente. Nenhum componente carboidrato foi detectado devido à negatividade às técnicas do $\mathrm{PAS}$, alcian blue $\mathrm{em} \mathrm{pH} 2,5 \mathrm{e} \mathrm{em} \mathrm{pH} 0,5$.
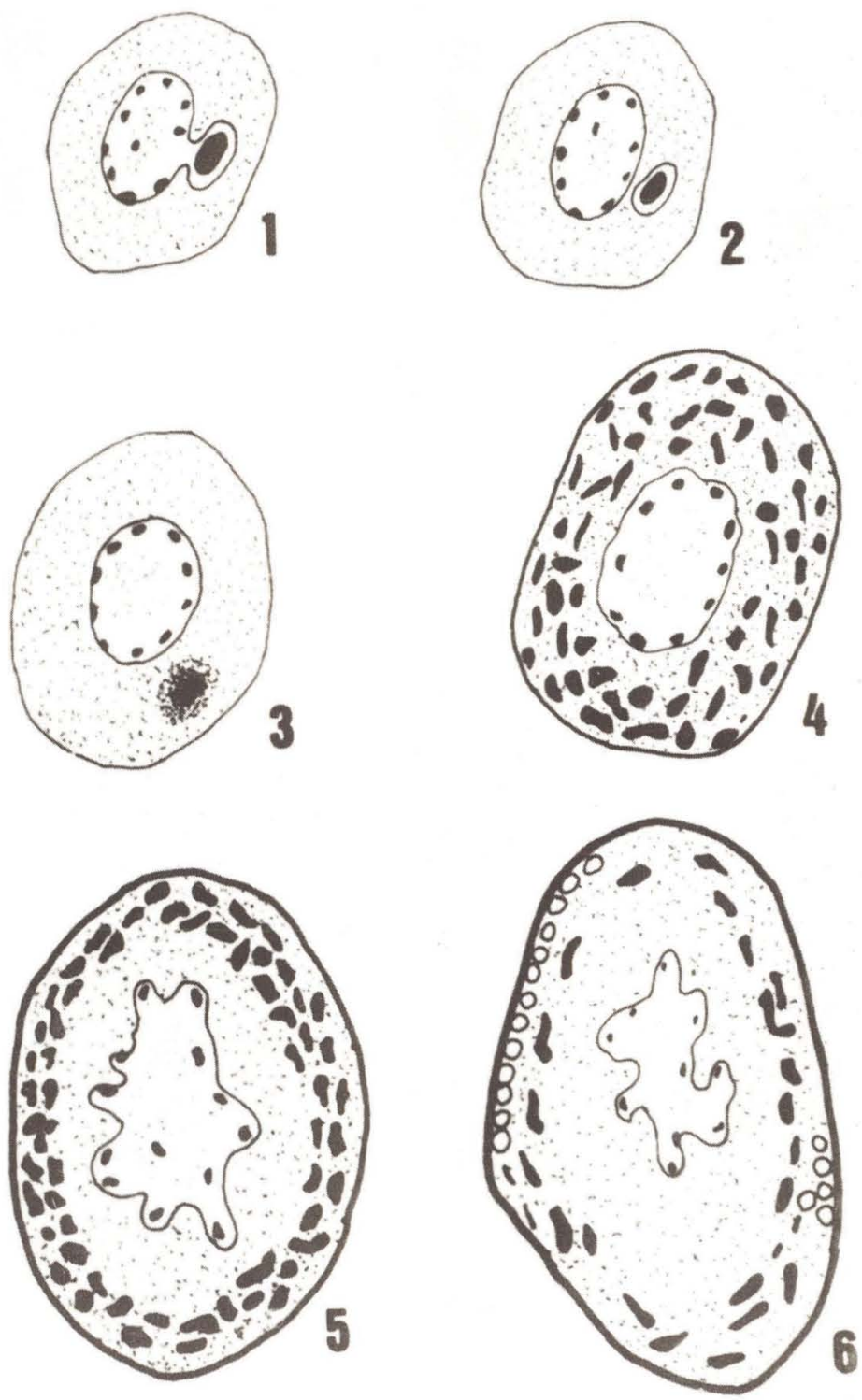

Figs. 1 a 6 - Desenho esquemático das 6 fases de desenvolvimento do núcleo vitelínico em ovócitos pré-vitelogênicos de $A$. bimaculatus. 
Revta bras. Zool.
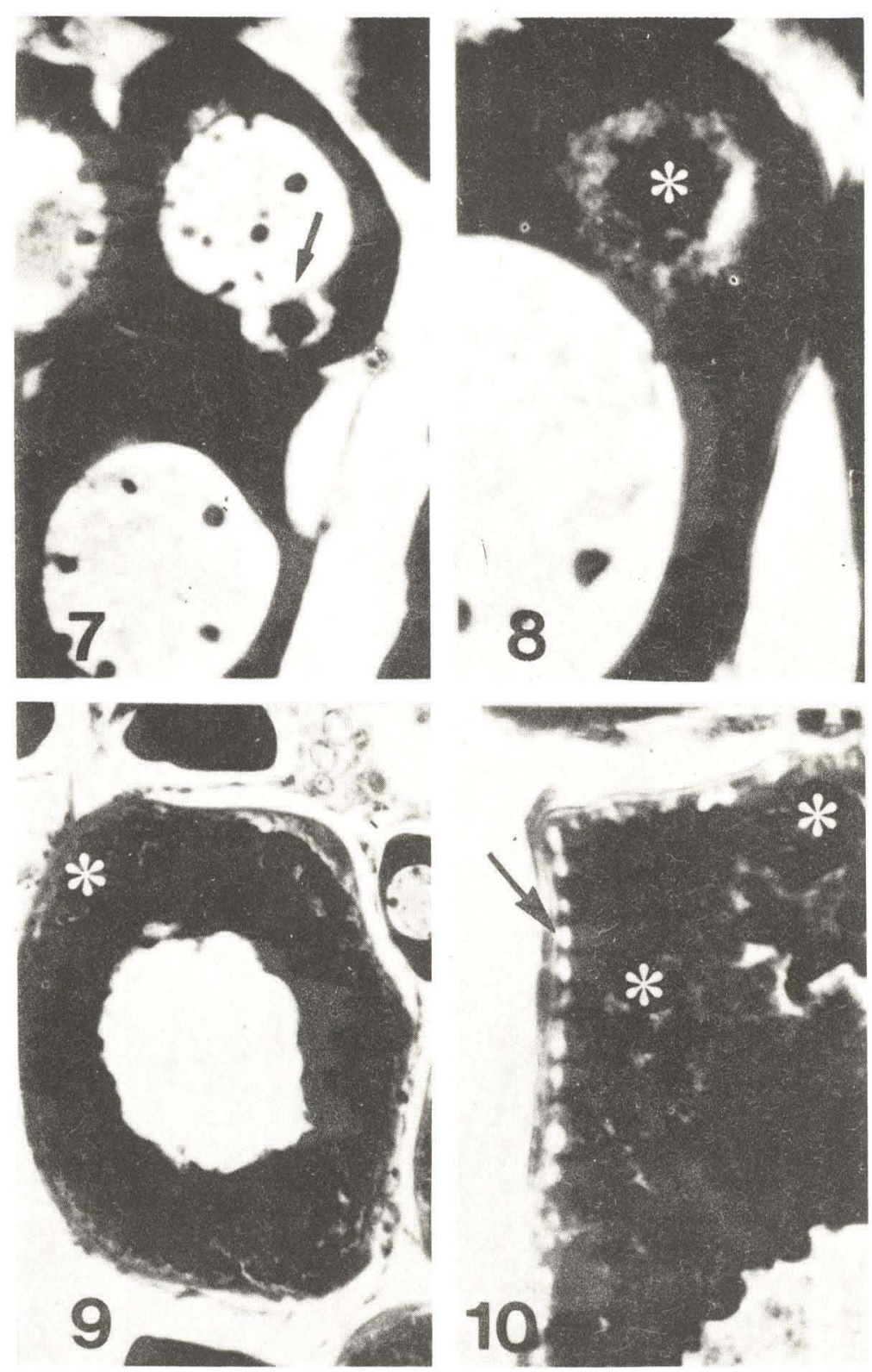

Figs. 7 a 10 - Morfologia do núcleo vitelínico durante seu desenvolvimento em ovócitos pré-vitelogênicos de $A$. bimaculatus. 7 - conecção ddo núcleo vitelínico com o núcleo do ovócito na fase 1. HE. 736X. 8 - o núcleo vitelínico na fase 3 é constituído de 2 regiões distintas: região central densa(*) rodeada por material finamente granular. HE. 1090X. 9 - o material do núcleo vitelínico forma um colar periférico de grânulos grosseiros na fase $5\left({ }^{*}\right)$. HE. $370 \mathrm{X} .10$ - na fase 6 , o material do núcleo vitelínico dispersa-se no ooplasma quando aparecem pequenas vesículas corticais (seta). T. Gomory. 990X. 


\section{DISCUSSÃO}

A maioria dos autores registrou a presença do núcleo vitelínico nos ovócitos prévitelogênicos de teleósteos (SHAHI et al., 1979; SAHAI \& BANNATWALA, 1989; SELMAN \& WALLACE, 1989 revisão; BAZZOLI \& RIZZO, 1990), coincidindo com nossas observações no lambari-do-rabo-amarelo, onde esta estrutura apresenta-se fortemente basófila e com um centro acidófilo conforme também descrito por BEAMS \& KESSEL (1973) e MAYER et al. (1988). Após revisão da literatura, GURAYA (1979) também relatou que, na maioria das espécies de teleósteos, o núcleo vitelínico é basófilo entretanto, SHAHI et al. (1979) descreveram núcleo vitelínico acidófilo em Channa punctatus.

A presença de halo claro bem definido circundando o núcleo vitelínico de $A$. $b i$ maculatum, coincide com as observações ao microscópio óptico de CHAUDHRY (1952), NAYYAR (1964), SHAHI et al. (1979). Segundo CHAUDHRY (1952) e NAYYAR (1964), este halo claro deve-se à retração do material provocada pela ação dos fixadores ou pela ação da parafina. No entanto, existe também a possibilidade desta região ser artefato de técnica resultante de extração de material durante o processamento histológico. No presente trabalho, o halo claro foi observado somente nas fases iniciais de desenvolvimento do núcleo vitelínico. Na fase 3, esta região é preenchida por material finamente granular que parece ser proveniente da dispersão do material da região densa central.

A literatura mostrou que existem variações no desenvolvimento do núcleo vitelinico de teleósteos. Em algumas espécies, ele origina-se próximo ao núcleo do ovócito e migra para o citoplasma periférico onde forma um colar de grânulos grosseiros antes de seu desaparecimento. Em outras espécies. não se observa a formação do referido colar. o núcleo vitelínico simplesmente migra para a periferia e seu conteúdo dispersa-se no citoplasma. Em $A$. bimaculatus, durante o desenvolvimento do núcleo vitelínico, forma-se o típico colar periférico de grânulos basófilos, semelhante àquele descrito por CHAUDHRY (1952), BEAMS \& KESSEL (1973), BEGOVAC \& WALLACE (1988), MAYER et al. (1988).

Reações histoquímicas indicaram a presença de proteínas e lípides no núcleo vitelínico do lambari-do-rabo-amarelo coincidindo com as observações de GURAYA (1963), NAYYAR (1964), THOMAS \& SATHYANESAN (1985) e ausência de carboidratos conforme os relatos de THOMAS \& SATHYANESAN (1985), CUSSAC \& MAGGESE (1986), MATKOVIC \& PISANQ (1989). Entretanto, ao contrário, NAYYAR (1964) constatou reação PAS-positiva nesta estrutura. Além destes componentes, o núcleo vitelínico de $A$. bimaculatus contém também RNA conforme também relatado por GURAYA (1963), NAYYAR (1964), BEAMS \& KESSEL (1973), AZEVEDO (1984).

$\mathrm{Na}$ presente investigação, observou-se continuidade entre o núcleo vitelínico recém-formado e o núcleo do ovócito. Este fato, associado à existência de nucléolos periféricos acolados à face interna do envoltório nuclear e à presença de RNA no núcleo vitelínico, sugere possivel origem nucleolar para esta estrutura. Nossas suposiçð̃es são reforçadas pelos relatos de DROLLER \& ROTH (1966) e BEAMS \& KESSEL (1973) que constataram, através de estudos ao microscópio eletrônico, material semelhante ao dos nucléolos no citoplasma. Estudos radioautográficos de AZEVEDO (1984) também indicam que, durante a ovogênese, há transporte contínuo de RNA e proteinas do nucléolo para o citoplasma e estas substâncias condensam-se na região perinuclear para for- 
mar o núcleo vitelínico ou corpos semelhantes a nucléolos. Além disso, passagem de material nucleolar para o citoplasma foi relatada, eṁ várias espécies de peixes, por CRUZ-LANDIM \& CRUZ-HOFLING (1979) que relacionaram este material com o plasma germinativo. GURAYA (1963) e NAYYAR (1964) não observaram o fenômeno de extrusão nucleolar e por isso negam a origem nuclear para o núcleo vitelínico.

Apesar da ocorrência do núcleo vitelínico ser bem documentada, seu significado funcional não está totalmente esclarecido. Sua participação na vitelogênese foi admitida por GURAYA (1963), NAYYAR (1964), SHAHI et al. (1979) e SAHAI \& BANNATWALA (1989) que associaram esta função com sua migração centrifuga e seu desaparecimento ao iniciar o processo de vitelogênese, o que foi também observado em $A$. bimaculatus no presente estudo. GURAYA (1979, revisão) reforça esta idéia e sugere que o núcleo vitelínico está envolvido na formação, multiplicação e acumulação de organelas necessárias à vitelogênese. De fato, estudos ao microscópio eletrônico mostraram que o núcleo vitelínico contém as organelas envolvidas na síntese de vitelo (SELMAN \& WALLACE, 1989 revisão). No mesmo sentido, BEGOVAC \& WALLACE (1988) acompanharam o desenvolvimento do núcleo vitelínico "in vitro" utilizando ovócitos corados vitalmente com rodamina 123 e acridina-orange, que indicam a presença de mitocôndrias e elementos lisosomais (corpos multivesiculares), respectivamente. Segundo estes autores, os corpos multivesiculares representam um compartimento precursor para a formação dos glóbulos de vitelo, devido ao fato de estarem envolvidos na degradação intracelular da vitelogenina. Adicionalmente, a sugestão de AZEVEDO (1984) que o núcleo vitelínico contém substâncias necessárias à maturação ribossomal pode também ser uma indicação de que esta complexa estrutura participa indiretamente da formação do vitelo protéico.

\section{AGRADECIMENTOS}

Ao PRPq/UFMG pelo auxilio financeiro e à bióloga Nádia M. Faria de Castro pela coleta do material.

\section{REFERÊNCIAS BIBLIOGRÁFICAS}

AZEVEDO, C., 1984. Development and ultrastructural autoradiographic studies of nucleolus-like bodies (nuages) in oocytes of a viviparous teleost (Xiphophorus helleri). Cell Tissue Res., 238: 121-128.

BAZZOLI, N. \& RIZZO, E., 1990. A comparative cytological and cytochemical study of the oogenesis in ten Brazilian teleost fish species. Eur. Arch. Biol. (Bruxelles), 101 (in press).

BEAMS, H.W. \& KESSEL, R.G., 1973. Oocy te structure and early vitelloge nesis in the trout, Salmo gairdneri. Am. J. Anat., 135: 105-122.

BEGOVAC, P.C. \& WALLACE, R.A., 1988. Stages of oocyte development in the pipefish, Syngnathu s scovelli. J. Morph., 197: 353-369.

CHAUDHRY, HS., 1952. The yolk-nucleus of Balbiani in teleostean fishes. Z. Zellforsch., 37 : $455-466$.

CUSSAC, V.E. \& MAGGESE, M.C., 1986. Oogenesis in Rhamdia sapo (Pisces, Pimelodidae). Stages of the oocyte, eegs envelopes and effects of the human chorionic gonadotropin. Rev. Brasil. Biol., 46 (1): 139-147.

CRUZ-L ANDIM, C. \& CRUZ-HOFLING, M.A., 1979. Comportamento dos nucléolos e mitocôndrios durante a ovogêne se de peixes teleósteos de água doce. Acta amazônica 9 (4): 723-728.

DROLLER, MJ. \& ROTH, T.F. 1966. An electron microscope study of yolk formation during oogenesis in Lebistes reticulatus Guppyi. J. Cell Biol. 28: 209-232.

GURAYA,S., 1963. Histochemical studies on the yolk-nucleus in fish oogenesis. Z. Zellforsch., 60: $659-666$. 
Vol. 7(3), 1990

GURAYA, S.S., 1979. Recent advances in the morphology, cytochemisty and function of Balbiani $s$ vite lline body in animal oocy tes. Int. Rev. Cytol., 59:249-321.

MATKOVIC, M. \& PISANÓ, A., 1989. Oogenesis and ovu lation in normal conditions or induced by homologous hypophysis in Hoplias m. malabaricus (Pisces, Erythrynidae). Rev. Brasil. Biol., 49 (1): 203-212.

MAYER, I.; SHACKLEY, S.E.; RYLAND, J.S., 1988. Aspects of the reproductive biology of the bass, Dicentrarchus labrax. L.I - An histological and histochemical study of oocy te development. J. Fish Biol., 33: 609-622.

NAYYAR, R.P., 1964. The yolk nucleus of fish oocytes. Quart. J. Micr. Sci., 105 (3): 353-358.

PEARSE, A.G.E., 1985. Histochemistry theoretical and applied. Vol. 2, 4 th. ed. Churchill Livingstone, Edinburgh, London, Melbourne and New Y ork, $1055 \mathrm{p.}$

SAHAI, S. \& BANNATWALA, R.C., 1989. The yolk nucleus in the fre shwater teleost Garra gotyla gotyla (gray). Folia Morp hologica, 37 (1): 1-3.

SELMAN, K. \& WALLACE, R.A., 1989. Review - Cellular aspects of oocyte growth in teleosts. Zool. Sci., 6:211-231.

S HAHI, R.N.P.; MISHRA, A.P. \& SINGH, B.R., 1979. S tudies on the formation of compound yolk in the developing oocytes of an air-breathing fish Channa puncatus (Bloch). Cytologia, 44: 397-408.

THOMAS, P.C. \& SATHYANESAN, A.G., 1985. Structure of the yolk nucleus in the previtellogenic o ocy tes of the teleost Amphipnous cuchia (Ham.). Mikroskopie (Wien), 42: 281-286. 